\title{
LONG-TERM FETAL OUTCOME AFTER FETAL CARDIAC BYPASS: FETAL SURVIVAL TO FULL TERM AND ORGAN ABNORMALITIES
}

V. Mohan Reddy, MD

John R. Liddicoat, MD

Judith R. Klein, MD

Richard K. Wampler, MD

Frank L. Hanley, MD
Background: Earlier work suggests that fetal cardiac bypass is technically feasible but results in significant placental dysfunction. Many of the stimuli that initiate this placental dysfunction have been identified in the past several years and these involve fetal stress, extracorporeal surfaces, priming substances (maternal blood), and flow characteristics. Fetal survival with conventional methods of bypass has been far less than optimal. A novel fetal bypass circuit requiring no priming volume was designed incorporating an in-line axial flow pump (Hemopump, Johnson \& Johnson Interventional Systems, Rancho Cordoya, Calif.) and was demonstrated to have a marked beneficial effect on placental function. Objective: The purpose of this study was to investigate the effect of this newly developed customized fetal bypass circuit on fetal survival and developing fetal organs. Methods and results: Nine fetuses at 122 to 126 days of gestation were subjected to fetal cardiac bypass via a transsternal approach, with a $16 \mathrm{~F}$ single right atrial venous cannula and a $12 \mathrm{~F}$ arterial cannula. Normothermic cardiac bypass was continued for 30 minutes at flow rates of $320 \pm 32 \mathrm{ml} / \mathrm{kg}$. Of the nine fetuses, one fetus was stillborn 4 days after bypass and eight $(89 \%)$ were delivered alive after progressing to term gestation. One lamb died of blunt trauma 1 day after birth. All other lambs $(n=7)$ thrived normally, and at 1 week of age they were subjected to autopsy. No gross hemorrhagic or thromboembolic lesions were detected in the organs examined including the brain. Microscopic examination of representative sections from all organs revealed mild pleural reaction in two lambs, and in two other lambs the hepatocytes showed evidence of mild increase in glycogen content, the significance of which is unknown in relation to fetal bypass. In one fetus that was aborted there was evidence of mild to moderate neuronal loss in the cerebral cortex. Conclusion: This study demonstrates that with improvements in fetal extracorporeal circuitry and techniques very favorable fetal outcome can be achieved. Further studies are necessary to evaluate the effects of bypass on fetal brain in an appropriate animal model. Advances in extracorporeal circuitry to suit the unique fetal physiology increase the possibility of future clinical application. (J Thorac Cardiovasc Surg 1996;111:536-44)
$A^{n}$ Ithough primary cardiac morphogenesis is complete by 8 weeks of intrauterine life, further development of the heart is substantially influenced

From the Division of Cardiothoracic Surgery, University of California San Francisco, San Francisco, Calif.

Read at the Twenty-first Annual Meeting of The Western Thoracic Surgical Association, Coeur d'Alene, Idaho, June 21-24, 1995.

Address for reprints: Frank L. Hanley, MD, 505 Parnașsus Ave., M593, San Francisco, CA 94143-0118.

Copyright (C) 1996 by Mosby-Year Book, Inc.

$0022-5223 / 96 \$ 5.00+0 \quad \mathbf{1 2 / 6 / 6 9 7 5 9}$ by fetal blood flow patterns. ${ }^{1}$ A structural abnormality that develops during primary morphogenesis can alter intracardiac blood flow patterns and cause important secondary morphologic consequences. After birth, these secondary structural lesions may pose a more serious management problem than the primary lesion itself. With recent advances in ultrasonic imaging, it is now possible to accurately diagnose structural heart defects as early as 12 weeks of gestation. ${ }^{2,3}$ Theoretically, if the primary lesion is corrected in utero the secondary morphologic consequences can be avoided. ${ }^{4}$

Many potentially useful surgical interventions in 
the fetus will need extracorporeal support. Because the fetus has a unique cardiovascular physiology, standard techniques of neonatal cardiopulmonary bypass need to be modified to preserve the milieu of the fetal-placental-maternal unit. Previous work ${ }^{5-10}$ has shown the feasibility of fetal cardiac bypass, but this work also identified the physiologic barriers to successful fetal cardiac bypass. Postbypass placental dysfunction is the most significant barrier, and a number of the mechanisms involved in this dysfunction have been identified. The stimuli causing placental dysfunction are fetal stress, extracorporeal surfaces, priming substarices, and flow characteristics. In our laboratory the beneficial effects of minimizing fetal stress and blocking placental dysfunction by inhibiting prostaglandin synthesis have been demonstrated. ${ }^{11-13}$ Our present focus is to study the effects of extracorporeal circuitiy on fetal metabolism, placental hemodynamics, and long-term fetal outcome. A customized fetal bypass circuit was designed incorporating an axial pump ${ }^{14}$ (Hemopump device, Johnson \& Johnson Interventional Systems, Rancho Cordova, Calif.) into the venous cannula. Short-term bypass studies were performed with this new circuit and the results were compared with results obtained with conventional roller pump circuits. Placental function and fetal hemodynamics were preserved significantly better with this new circuit even without pharmacologic blunting of the fetal stress response or inhibition of prostaglandin synthesis. In the present study long-term fetal outcome was investigated with this newly designed bypass circuit.

\section{Methods}

Surgical preparation. Nine mixed-breed pregnant ewes (at $124 \pm 1.1$ days of gestation; term $=145$ days) were fasted for 24 hours before the study. On the day of the study the ewe was premedicated with ketamine $(10 \mathrm{mg} / \mathrm{kg}$ intramuscularly) and buprenorphine $(0.01 \mathrm{mg} / \mathrm{kg}$ intramuscularly). Epidural spinal anesthesia was achieved with $4 \mathrm{ml}$ of $1 \%$ tetracaine hydrochloride. The ewe was then placed supine on the operating table and lightly fastened. The maternal anesthesia was maintained with intravenous ketamine infusion at a rate of 3 to $5 \mathrm{mg} / \mathrm{kg}$ per hour. A 16-gauge central venous catheter was placed into the jugular vein. Maternal heart rate, arterial pressure, and central venous pressure were monitored and lactated Ringer's solution was administered at a rate of $4 \mathrm{ml} / \mathrm{kg}$ per hour.

A midline laparotomy was performed and the uterus was exposed. By gentle palpation the number and orientation of the fetuses were determined (single fetus, $n=5$; twins, $n=4$ ). A hysterotomy was made over the fetal chest and the fetal forelimbs were extracted. Fetal anesthesia was achieved with ketamine (10 $\mathrm{mg} / \mathrm{kg}$ intramuscularly). In addition succinylcholine hydrochloride $(2 \mathrm{mg} / \mathrm{kg}$ intramuscularly) was administered to prevent fetal breathing movements. After a few minutes the fetus was gently supinated to expose the sternum. A 20-gauge central venous catheter was placed into the jugular vein to monitor the fetal central venous pressure and to administer intravenous fluids. Midline fetal sternotomy was performed and a 20-gauge arterial catheter was placed into the right internal thoracic artery and advanced into the subclavian artery. Pericardiotomy was performed and the heart was exposed. Purse-string sutures (5-0 Prolene polypropylene, Ethicon, Inc., Somerville, N.J.) were placed on the main pulmonary artery $(n=5)$ or the ascending aorta $(n=4)$ and on the superior vena cava just proximal to its junction with the right atrium. Fetal cardiac bypass was performed according to the protocol outlined herein.

After cessation of the bypass, hemostasis was secured, all cannulas and catheters were removed, and the fetal chest was closed. The hysterotomy was closed after replacement of the amniotic fluid with warm saline solution and administration of antibiotics (2 million units of penicillin $\mathrm{G}$ procaine and $100 \mathrm{mg}$ of gentamicin sulfate). The maternal laparotomy was repaired and the ewe was returned to the pen. All animals received standard postoperative care. Antibiotics ( 2 million units of penicillin $G$ procaine and $100 \mathrm{mg}$ of gentamicin sulfate) were administered intravenously to the ewe during the operation and intramuscularly daily thereafter for 5 days. The ewes were allowed to progress to term and deliver normally.

Experimental protocol

Extracorporeal circuit. The circuit is illustrated in Fig. 1. The Hemopump device ${ }^{14}$ is a miniature axial flow pump. It was incorporated into the proximal end of the venous cannula and the drive cable was brought out through one limb of the Y connector. A short segment of a quarterinch polyvinyl tubing containing an in-line flow probe was attached to the other limb of the $\mathrm{Y}$ connector. To this tubing the arterial cannula was connected, thereby forming a closed loop system. The total capacity of the circuit was 14 to $16 \mathrm{ml}$. Thus no priming was necessary. The circuit was filled with fetal blood at the time of cannulation.

Fetal cardiac bypass. Fetal weight was estimated on the basis of the gestational age by means of a standard nomogram. ${ }^{15}$ A $300 \mathrm{U} / \mathrm{kg}$ dose of heparin was given intravenously to the fetus via the superior vena cava. The right atrium was cannulated via the superior vena cava with a $16 \mathrm{~F}$ angled-tip venous cannula (DLP, a division of Medtronics, Grand Rapids, Mich.) and the bypass circuit was filled with fetal blood and deaired. A $12 \mathrm{~F}$ arterial cannula (Electro-Catheter Corp. Rahway, N.J.) was placed in the main pulmonary artery $(n=5)$ or the ascending aorta $(n=4)$ and was filled with fetal blood and deaired. The arterial and venous componens of the circuit were connected and the bypass was initiated. Pump flows were continuously monitored with an in-line ultrasonic flow probe (Transonic Systems, Inc., Ithaca, N.Y.). Bypass was continued for 30 minutes. Fetal blood gases were measured immediately before bypass, at 15 minutes of bypass, and immediately after cessation of bypass. 


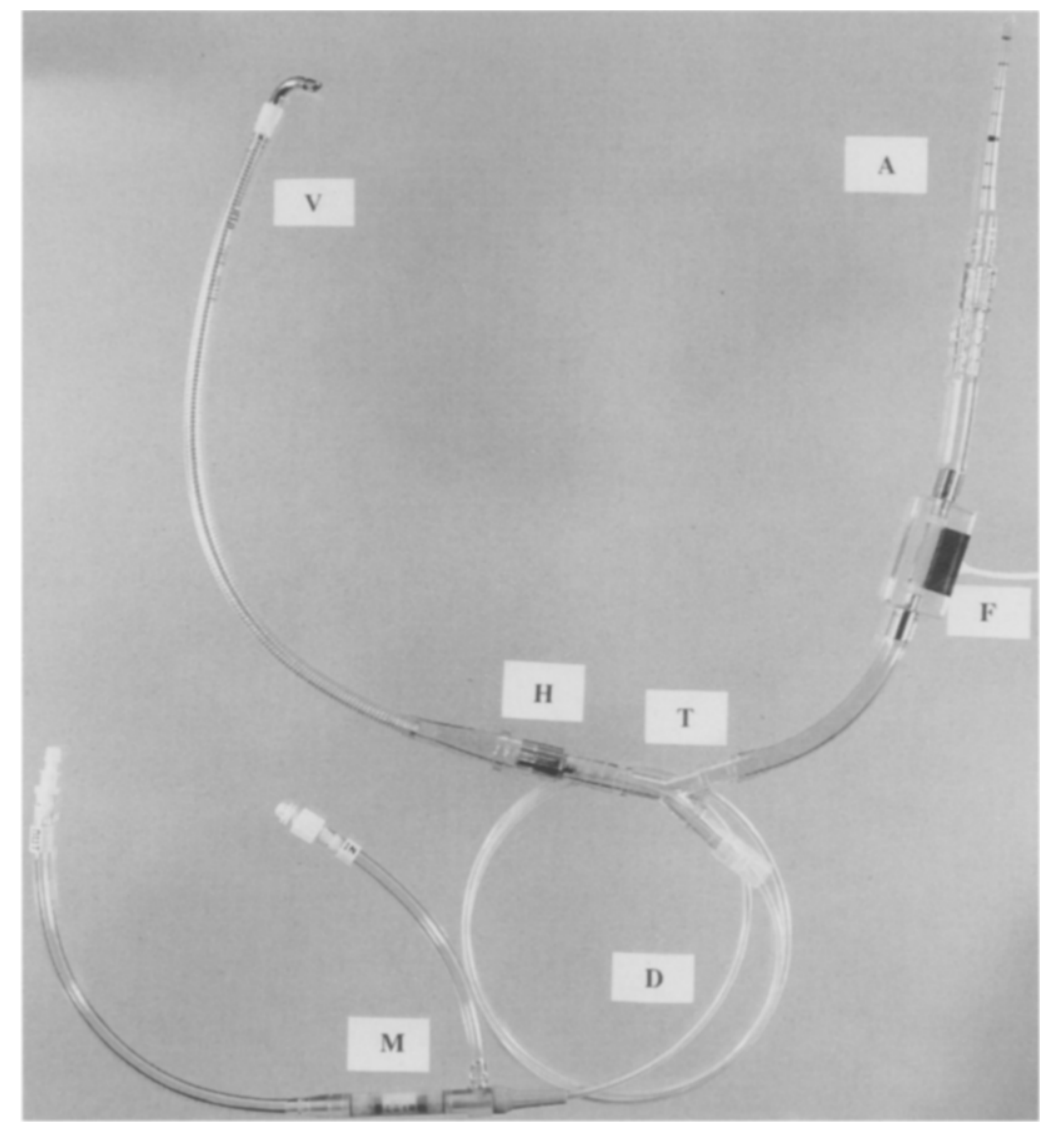

Fig. 1. Fetal cardiac bypass circuit: $A$, Arterial cannula; $D$, drive cable; $F$, flow probe; $H$, Hemopump device $^{14} ; M$, electromagnet; $T$, Y connector; $V$, venous cannula.

Blood samples for fetal arterial blood gases were drawn from the subclavian artery. Fetal hemoglobin concentration and oxygen saturation were estimated before and after bypass. After the discontinuation of bypass and decannulation, hemostasis was secured, all catheters were removed, and the fetal sternotomy was closed.

Data acquisition. Fetal and maternal systemic arterial pressures and fetal and maternal central venous pressures were measured with Statham P23Db pressure transducers (Statham Instruments, Division of Viggo-Spectramed, Inc., Critical Care Div., Oxnard, Calif.). Mean pressures were obtained by electrical integration. Heart rate was measured by a cardiotachymeter triggered from the phasic systemic arterial pressure pulse wave. Pump flow was measured on an ultrasonic flowmeter (Transonic). All hemodynamic variables were continuously recorded on a Gould multichannel electrostatic recorder (model TA11, Gould Inc., Cleveland, Ohio). Systemic arterial blood gases and $\mathrm{pH}$ were measured on a Corning $158 \mathrm{pH} / \mathrm{blood}$ gas analyzer (Corning Medical and Scientific, Medfield, Mass.). Hemoglobin concentration and oxygen saturation were measured by a hemoximeter (model OSM 2, Radiometer A/S, Copenhagen, Denmark).

Neonatal lamb study. At birth the lambs were weighed and clinically examined by an experienced veterinarian. At
1 week of age the lambs were weighed again and clinically examined. The lambs were then put to death with an overdose of pentobarbitol and an autopsy was performed. All body cavities and viscera were examined. The brain, heart, liver, spleen, both lungs, and both kidneys were harvested and stored in $10 \%$ formaldehyde solution for later pathologic examination.

All animals received humane care in compliance with the "Principles of Laboratory Animal Care" formulated by the National Society for Medical Research and the "Guide for the Care and Use of Laboratory Animals" prepared by the Institute of Laboratory Animal Resources and published by the National Institutes of Health (NIH Publication No. 86-23, revised 1985). The experimental protocol was approved by the Committee for Animal Care at the University of California San Francisco.

Pathology. Gross and microscopic examination of the organs was performed by a veterinary pathologist (all organs), a cardiac pathologist (all organs except the brain), and a neuropathologist (only brains). Serial transverse sections (about $0.5 \mathrm{~cm}$ thick) of the hearts were examined for any gross abnormality. Representative sections were taken for microscopic examination from the right ventricular free wall, left ventricular free wall, and the interventricular septum. The brains were sectioned 
Table I. Fetal bypass data and outcome

\begin{tabular}{|c|c|c|c|c|c|c|c|c|c|c|c|c|c|c|}
\hline $\begin{array}{l}\text { No. of } \\
\text { fetuses }\end{array}$ & $p H^{*}$ & $p H \dot{t}$ & $p H+$ & $\begin{array}{c}p H \\
\text { change }\end{array}$ & $\mathrm{PCO}_{2}{ }^{*}$ & $\mathrm{PCO}_{2} \dagger$ & $\mathrm{PCO}_{2}+\mathrm{t}$ & $\begin{array}{c}\mathrm{PCO}_{2} \\
\text { change }\end{array}$ & $\mathrm{PO}_{2}{ }^{*}$ & $\mathrm{PO}_{2} \dagger^{\dagger}$ & $\mathrm{PO}_{2}+$ & $\begin{array}{c}\mathrm{PO}_{2} \\
\text { change } \\
\end{array}$ & $P F$ & Outcome \\
\hline Single & 7.38 & 7.34 & 7.29 & 0.09 & 42.10 & 43.20 & 45.00 & 2.90 & 24.00 & 23.10 & 20.10 & 3.90 & 300 & Alive \\
\hline Single & 7.39 & 7.35 & 7.29 & 0.10 & 35.20 & 42.10 & 48.10 & 12.90 & 19.60 & 19.20 & 18.20 & 1.40 & 360 & Alive \\
\hline Twins & 7.37 & 7.35 & 7.30 & 0.07 & 45.00 & 49.40 & 51.90 & 6.90 & 22.60 & 21.60 & 20.70 & 1.90 & 300 & Alive \\
\hline Single & 7.35 & 7.30 & 7.21 & 0.14 & 45.90 & 54.20 & 60.00 & 14.10 & 21.60 & 17.20 & 16.00 & 5.60 & 324 & Dead \\
\hline Twins & 7.41 & 7.36 & 7.28 & 0.13 & 39.20 & 50.10 & 52.90 & 13.70 & 24.10 & 23.60 & 20.90 & 3.20 & 300 & Alive \\
\hline Single & 7.43 & 7.40 & 7.35 & 0.08 & 41.40 & 43.20 & 48.90 & 7.50 & 26.90 & 24.10 & 21.30 & 5.60 & 271 & Alive \\
\hline Twins & 7.47 & 7.42 & 7.40 & 0.07 & 40.30 & 40.80 & 45.60 & 5.30 & 31.20 & 28.50 & 23.10 & 8.10 & 330 & Alive \\
\hline Twins & 7.42 & 7.38 & 7.32 & 0.10 & 42.00 & 43.10 & 44.00 & 2.00 & 25.70 & 22.90 & 21.80 & 3.90 & 375 & Alive \\
\hline Single & 7.37 & 7.33 & 7.29 & 0.08 & 47.60 & 48.10 & 52.50 & 4.90 & 22.40 & 23.70 & 22.10 & 0.30 & 324 & Alive \\
\hline Mean & 7.40 & 7.36 & 7.30 & 0.10 & 42.08 & 46.02 & 49.88 & 7.80 & 24.23 & 22.66 & 20.47 & 3.77 & 320.49 & \\
\hline SD & 0.04 & 0.04 & 0.05 & 0.03 & 3.76 & 4.56 & 5.04 & 4.66 & 3.40 & 3.19 & 2.17 & 2.42 & 32.24 & \\
\hline
\end{tabular}

Changes in $\mathrm{pH}$, carbon dioxide tension $\left(\mathrm{PCO}_{2}\right)$, and oxygen tension $\left(\mathrm{PO}_{2}\right)$ are calculated as the difference between the prebypass and postbypass parameters The change in $\mathrm{pH}, \mathrm{PCO}_{2}$, and $\mathrm{PO}_{2}$ did not correlate with fetal death (linear regression; adjusted $R^{2}=0.235 ; p=0.263$. Pump flow ( $P F$ ) is expressed as milliliters per kilogram of estimated fetal weight. SD, Standard deviation.

*Before bypass.

†At 15 minutes of bypass.

\#Immediately after bypass.

$(0.5 \mathrm{~cm}$ thick $)$ in accordance with the clinical method and examined for any gross abnormality. Representative sections were then taken from the cerebral cortex (motor), basal ganglia, and cerebellum for microscopic examination. Similarly, the lungs, liver, spleen, and kidneys were examined for any gross abnormalities. Representative sections were then taken from the upper and lower lobes of both lungs, from both lobes of the liver, from the spleen, and from both kidneys. All the representative sections were stained with hematoxylin and eosin stain by standard techniques.

Data analysis. Fetal blood gas parameters, pump flows, and animal weights are expressed as mean \pm standard deviation. The absolute change in $\mathrm{pH}$, carbon dioxide tension, and oxygen tension during bypass was calculated as the difference between the immediate prebypass and immediate postbypass $\mathrm{pH}$, carbon dioxide tension, and oxygen tension. This change in blood gas parameters was correlated with the fetal outcome by linear regression analysis (SPSS for Windows, version 6.01; SPSS Inc., Chicago, Ill.).

\section{Results}

Bypass data. Fetal bypass data are summarized in Table I. The absolute difference in prebypass and postbypass blood $\mathrm{pH}$, carbon dioxide tension, and oxygen tension did not correlate with fetal death (linear regression; adjusted $R^{2}=0.235 ; p=0.263$ ).

Long-term survival. Eight of the nine fetuses $(88 \%)$ progressed to term and were delivered normally. All twin fetuses $(n=4)$ including the unoperated twin were delivered normally. Of the five single fetuses, one was stillborn 4 days after fetal bypass. At autopsy there was no evidence of bleeding into the body cavities or any gross evidence of organ damage.
Postnatal course. The weight of the lambs $(n=$ 8 ) at birth and at 1 week of age $(n=7)$ was within normal limits for the lambs (Fig. 2). All animals appeared healthy with well-healed sternotomy scars. One lamb died 24 hours after birth of blunt trauma after being trampled. The other seven lambs thrived and progressed normally until 1 week of age, when they were studied.

Pathology results. Myocardial architecture was essentially normal (Fig. 3) with no evidence of thromboembolic or hemorrhagic lesions and no evidence of hypoxic damage. In the fetus that died 4 days after bypass, the cerebral cortex showed mild to moderate neuronal loss (Fig. 4) and mild astrogliosis. Both are suggestive of tissue injury from hypoxia or low perfusion. In all survivors, the cerebral cortex (Fig. 5) and basal ganglia were normal. The Purkinje neurons, which are sensitive to hypoxia, were normal in all the lambs (Fig. 6). No evidence of intracerebral or intraventricular hemorrhage was detected in any of the lambs or the stillborn fetus. The liver in the stillborn fetus showed evidence of mild venous congestion. Two survivors had a mild increase in glycogen content of the liver. In all the others the liver was essentially normal. All animals had normal pulmonary architecture. Evidence of mild pleural thickening was seen in three lambs. In the stillborn fetus the lung was immature with evidence of mild congestion. The spleen and kidneys did not show any evidence of hemorrhage, infarction, or hypoxic damage in any of the lambs. 


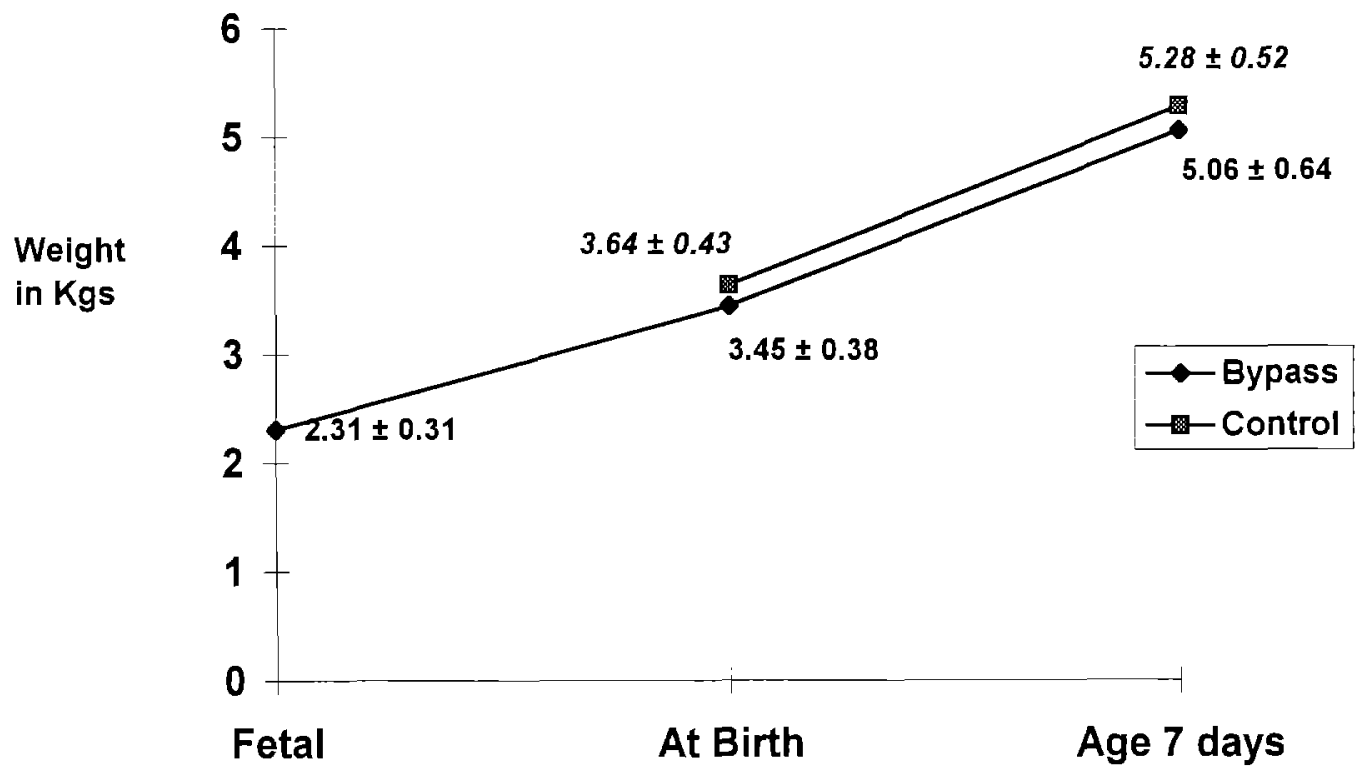

Fig. 2. Weight of the study lambs (fetuses, $n=9$; newborn, $n=8 ; 7$ days old, $n=7$ ) and normal lambs $(n=5)$. The growth of the lambs delivered after fetal cardiac bypass was similar to that of normal lambs.

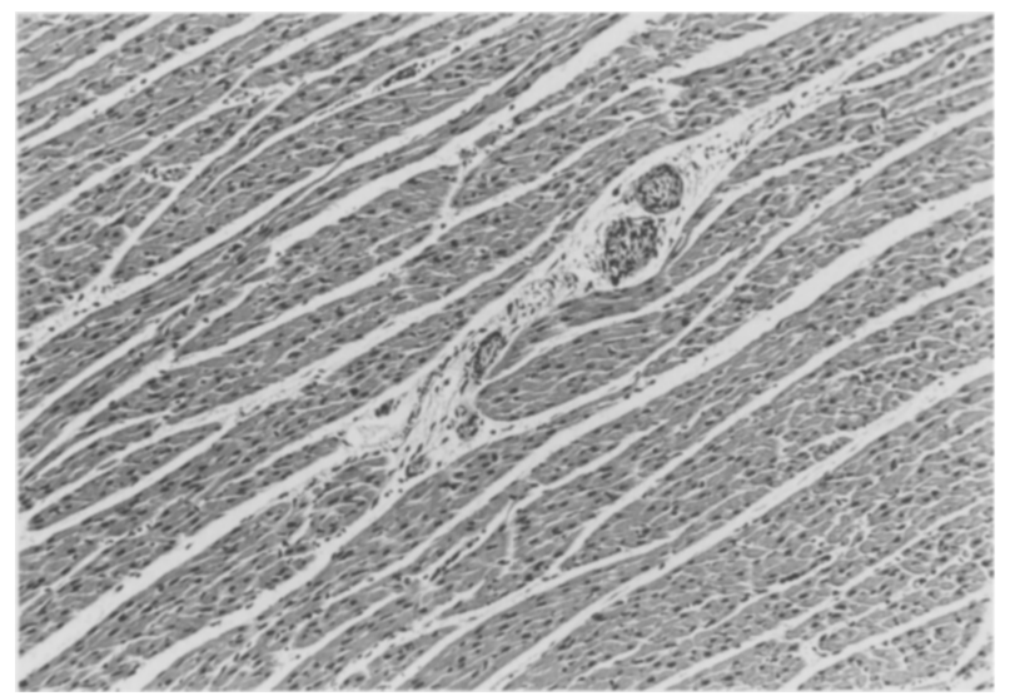

Fig. 3. Microscopic appearance $(\times 100)$ of the left ventricular free wall showing normal myocardial cells and fiber architecture.

\section{Discussion}

The sheep is an excellent model for studying fetal extracorporeal techniques. A wealth of information on basic fetal physiology is available, which provides an excellent background for evaluating the pathologic responses that occur after fetal extracorporeal circulation. Additionally, inasmuch as the fetal sheep is about the size of the human fetus, critical technical issues can be appropriately assessed.
Early studies ${ }^{5,6}$ of fetal extracorporeal circulation indicated that technical problems were easily solved, but the pathophysiologic responses of the fetalplacental-maternal unit to fetal extracorporeal circulation were challenging. The major obstacle to successful fetal extracorporeal circulation is that it directly causes increased placental vasoconstriction leading to the development of placental dysfunction. Another important issue was that the fetal response 


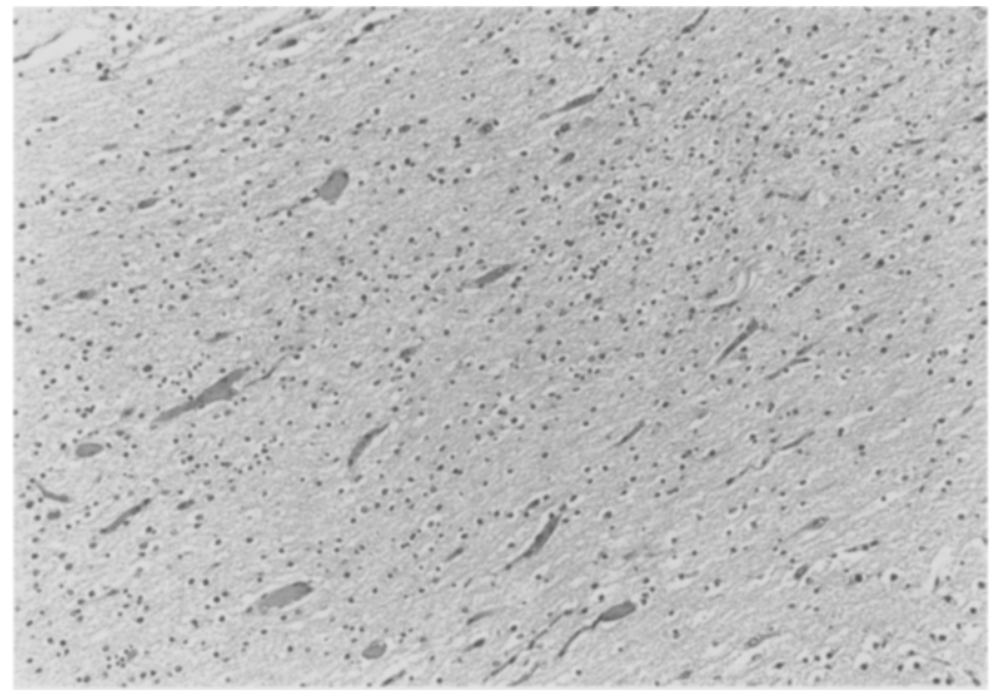

Fig. 4. Microscopic appearance $(\times 100)$ of a section from the cerebral cortex of a fetus that died after fetal cardiac bypass. Note the cortical neuronal loss, which is suggestive of hypoxia or low flow to the brain.

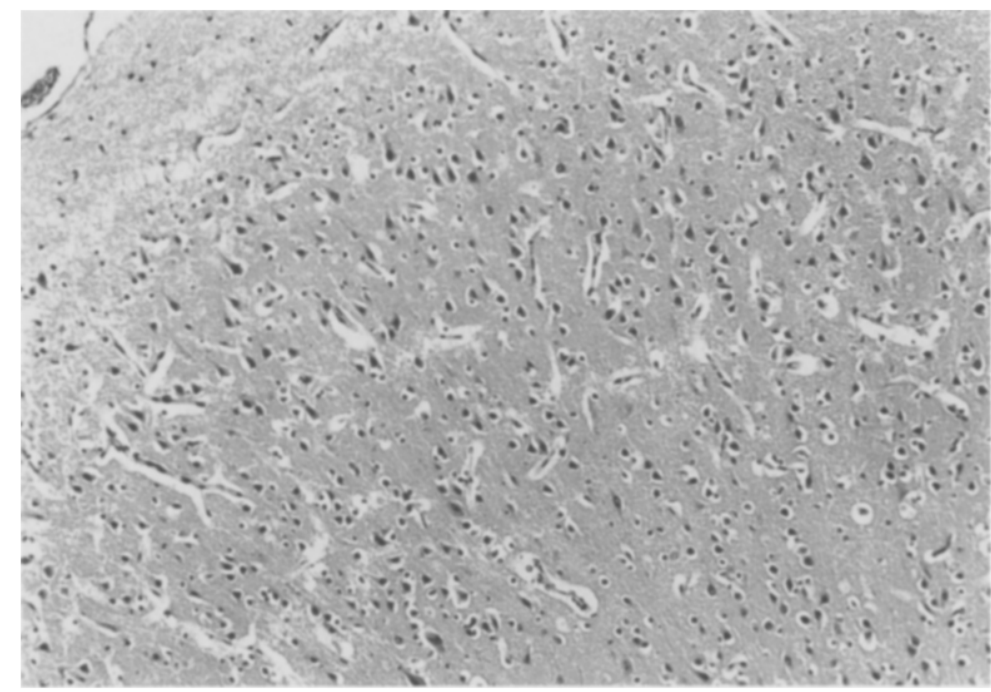

Fig. 5. Microscopic appearance $(\times 100)$ of cerebral cortex of a lamb that was subjected to fetal cardiac bypass as a fetus. No abnormalities were noted.

to surgical stress led to cardiovascular instability and subsequent secondary placental dysfunction.

When the direct effects of extracorporeal circulation on the placenta and the fetal response to surgical stress were not addressed, fetuses survived for only minutes to hours after fetal bypass. When these negative responses were carefully managed, fetal hemodynamics and placental function were significantly preserved. ${ }^{11-13}$ With these techniques a $40 \%$ fetal survival to term was achieved. ${ }^{16}$ Although achieving fetal survival was an important advance, the overall outcome was still poor. We hypothesized that improvements in bypass circuitry might further improve the tolerance of the fetus to extracorporeal circulation. A new bypass circuit was designed with the incorporation of an in-line axial flow pump (Hemopump device) in the venous cannula. With this new circuit the extracorporeal surface was markedly reduced and, importantly, external priming volume was completely avoided. Short-term studies ${ }^{17}$ were performed comparing this circuit with the conventional circuit while at the same time 


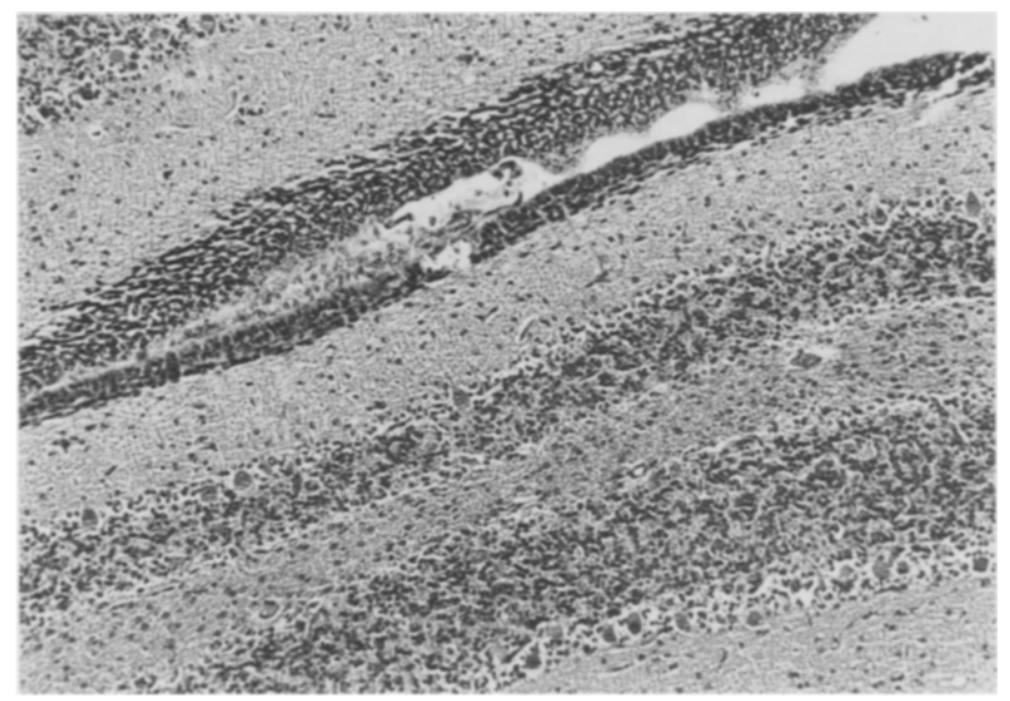

Fig. 6. Microscopic appearance $(\times 100)$ of a cerebellar section of a lamb (long-term survivor after fetal cardiac bypass). Note that the Purkinje neurons look normal.

avoiding our previously developed techniques of blunting the stress response or blocking prostaglandin synthesis. This study was designed in this fashion to isolate as much as possible the influence of the extracorporeal circuitry itself. Fetal cardiac bypass was performed via a midline sternotomy with extensive fetal instrumentation. This study showed that minimizing fetal extracorporeal circuitry and avoiding priming volume resulted in significant improvement in placental function.

The present long-term study was then undertaken to determine the influence of these beneficial effects on long-term fetal survival. Eight $(89 \%)$ of the fetuses survived to term gestation and were delivered normally. One fetus was aborted 4 days after fetal bypass. Autopsy was not suggestive of any definitive cause of death. Death may have been due to progression of placental dysfunction or to metabolic issues, which need to be addressed. After birth the progress of these lambs was observed for 1 week. One lamb died 24 hours later of blunt trauma caused by trampling. The remaining seven lambs grew normally with appropriate weight gain at 1 week of age.

The current study is significant in many ways. First, it demonstrates that survival to term can be achieved after transsternal, clinically applicable methods of bypass. Second, and more important, it demonstrates that improvements in extracorporeal circuitry will significantly minimize the perturbation of the fetal-placental-uterine milieu after fetal cardiac bypass.

It appears from our more recent studies that although pharmacologic management of fetal stress is undoubtedly important and inhibition of prostaglandin synthesis protects the placenta, minimizing the stimuli (i.e., extracorporeal surfaces and priming substances) that initiate the pathophysiologic mechanisms is much more important. In essence, the new bypass circuitry is preventive whereas the pharmacologic management is not, but rather treats the end organ response. We believe the former approach to be much more sound.

One critique of this circuit is that it is extremely simple. For example, it has no mechanism for preventing air embolism from the venous cannulation site if the venous line pressure becomes subatmospheric. This is a highly valid concern and necessary improvements are being further evaluated in our laboratory. With proper regulation of flows and aggressive intravenous fluid administration to the fetus, we did not encounter any observable air embolism during the 30-minute bypass period in any of the fetus. To confirm this, we examined all major organs and detected no evidence of thromboembolic and hypoxic damage in any of the survivors. The one fetus that was aborted 4 days after bypass showed evidence of mild to moderate cortical neuronal loss and astrogliosis. Both these findings are suggestive of low perfusion or hypoxic damage. Indeed they 
probably could be the result of progressive hypoxia after bypass, which may have resulted in the death of this fetus. Of note, no hemorrhagic lesions were found in the brain. However, the sheep is not a good model for evaluation of cerebral and intraventricular bleeding because the germinal matrix matures relatively early in the sheep fetus.

In summary, this study shows that with improvements in extracorporeal techniques favorable fetal survival to term is possible after fetal cardiac bypass. However, the improved results may also be partly due to better understanding of the fetal-placental unit and general experience with fetal surgical techniques. Further modifications are necessary to make the bypass circuit more safe for possible clinical application in the future. Also, cerebral effects of bypass should be evaluated in a more appropriate animal model.

We acknowledge the technical help and support of Walid K. Abol Hosn, and Mike Wright of Johnson \& Johnson Interventional Systems, Rancho Cordova, California. We also thank Danny Lau, DVM, Phil Ursell, MD, and Andrew Bonnel, $\mathrm{MD}$, for providing their expertise in organ pathology.

\section{REFERENCES}

1. Rose V, Clark LE. Etiology of congenital heart disease. In: Freedom RM, Benson LN, Smallhorn JF, eds. Neonatal heart disease. London: Springer-Verlag, 1992:3-13.

2. Silverman NH, Golbus MS. Echocardiographic techniques for assessing normal and abnormal fetal cardiac anatomy. $\mathbf{J}$ Am Coll Cardiol 1985;5:20S-9S.

3. Dolkart LA, Reimers FT. Transvaginal fetal echocardiography in early pregnancy: normative data. Am J Obstet Gynecol 1991;165:688-94.

4. Hanley FL. Fetal cardiac surgery. Advances in cardiac surgery. Vol. 5. St. Louis: Mosby-Year Book, 1994.

5. Richter RC, Slate RK, Rudolph AM, et al. Fetal blood flow during hypothermic cardiopulmonary bypass in utero [Abstract]. J Cardiovase Surg 1985;26:86.

6. Bradley SM, Hanley FL, Duncan BW, Jennings RW, Verrier ED. Fetal cardiac bypass alters regional blood flows, arterial blood gases and hemodynamics in sheep. Am $\mathbf{J}$ Physiol 1992;263:H919-28.

7. Assad RS, Lee F-Y, Bergner K, Hanley FL. Extracorporeal circulation in the isolated in situ lamb placenta: hemodynamic characteristics. J Appl Physiol 1992;72:2176-80.

8. Assad RS, Lee F-Y, Sabik JF, Mackenzie S, Hanley FL. Tolerance of placenta to normothermic circulatory arrest. J Matern Fetal Invest 1992;2:145-50.

9. Sabik JF, Assad RS, Hanley FL. Halothane as an anesthetic for fetal surgery. J Pediatr Surg 1993;28:542-7.

10. Hanley FL. Fetal responses to extracorporeal circulatory support. Cardiol Young 1993;3:263-72.

11. Sabik JF, Assad RS, Hanley FL. Prostaglandin synthesis inhibition prevents placental dysfunction after fetal cardiac bypass. J THorac Cardiovasc Surg 1994;103:733-42.
12. Sabik JF, Heinemann MK, Assad RS, Hanley FL. High dose steroids prevent placental dysfunction after fetal cardiac bypass. J Thorac Cardiovasc Surg 1994;107:116-25.

13. Fenton KN, Heinemann MK, Klautz RJM, Liddicoat JR, Hanley FL. Inhibition of fetal stress response improves cardiac output and gas exchange after fetal cardiac bypass. J Thorac Cardiovasc Surg 1994;107:1416-22.

14. Butler KC, Moise JC, Wampler RK. The hemopump--A new cardiac prosthesis device. IEEE Trans Biomed Eng 1990;37:193-6.

15. Barcroft J. Researches on pre-natal life. Oxford: Blackwell, 1977:29-51.

16. Fenton KN, Zinn HE, Heinemann MK, Liddicoat JR, Hanley FL. Long-term survivors of fetal cardiac bypass in lambs. J ThORAC CARDIOVASC SURg 1994;107:1423-7.

17. Reddy VM, Liddicoat JR, Klein JR, McElhinney DB, Wampler RK, Hanley FL. Hemodynamic advantages of using an in-line axial flow pump to minimize extracorporeal surface and avoid priming volume in fetal cardiac bypass. Ann Thorac Surg [In press].

\section{Discussion}

Dr. Edward D. Verrier (Seattle, Wash.). This work is a continuum of the extensive basic science and clinical work originating from the University of California San Francisco (UCSF) investigating fetal physiology and potential clinical fetal intervention. The key scientific advance promulgated by this investigation is the use of the small Hemopump device located in the venous cannula. With this approach, the priming volume of the circuit is small and the exposure of blood to the artificial surfaces is minimized. Eight of the nine fetuses progressed to delivery and only one of the survivors had histologic evidence of organ injury.

I have no specific questions for Dr. Reddy because I believe the work is essentially self-explanatory. This innovative technique appears to be step forward in improving the safety of cardiopulmonary bypass in fetuses. My questions are more philosophical, and I believe a discussion of where this productive area of research is headed might be of interest to a largely clinically oriented audience.

The sheep model has been very productive in all studies of fetal physiology, but it is significantly different from primates in terms of cardiovascular, placental, and maternal physiology. From an investigative standpoint, are we at the point at which nonhuman primate studies are indicated? Have there been significant improvements in tocolytic therapy, which is one of the common limiting factors in human interventions? Have you thought about the cost of such research and some of the issues involved with that next step?

Dr. Reddy. We have made substantial progress in terms of fetal cardiac research in sheep, and I agree that it is time now to examine some important issues in primates. We have performed initial studies in primates and the placental response to fetal extracorporeal circulation is identical to that in sheep.

The cost of primate research is very high: one pregnant rhesus monkey costs about $\$ 3500$. We are, however planning further work in primates because of the importance of these studies. 
A number of tocolytic agents have been examined by Dr. Harrison's group at UCSF. They have had some success in human beings with nitric oxide donors, especially nitroprusside. They are currently investigating the agents more specific to the uterus, which have fewer systemic side effects.

Dr. Verrier. Dr. Michael Harrison initiated the clinical fetal treatment program at UCSF more than 20 years ago. Initially there was great hope that fetal intervention would substantially improve the outcomes in congenital diaphragmatic hernia, ureteral and urethral obstruction, hydrocephalus, and some fetal tumors. A number of spectacular results have been obtained. However, in recent discussions with Dr. Harrison, I have learned that the indications for fetal intervention have significantly narrowed. The thrust of their present research is focused on in utero immunologic molecular and genetic manipulation. No other clinical fetal treatment program has emerged elsewhere in the world. Are there lessons to learn from that experience? Cardiopulmonary bypass adds another complex variable to simple maternal and fetal transgression.

Dr. Reddy. The concerns that you have raised are all very important. The rationale for fetal intervention is based on the premise that if a defect is corrected in utero, the developing fetus will have the remainder of the gestation to recover and the secondary morphologic sequelae will be prevented or minimized. The main stumbling block has been premature delivery. The benefit of fetal surgery is lost if the fetus is delivered prematurely. Therefore prevention of premature labor by effective tocolytic therapy is an important area of investigation.

Progress has been slow in the field of fetal surgery. However, the enthusiasm has not been dampened, because at least three young investigators from various centers in the United States have visited our laboratory in the past year, and some from abroad continue to correspond with us and have started work in their centers.

Dr. Verrier. Widespread use of echocardiography in high-risk pregnancies has identified congenital heart lesions earlier. Many of these complex lesions can be diagnosed at 12 weeks' gestation. Lindsay Allen, who is one of the premier pediatric cardiologists in the world, from Great Ormond Street, London, has written and spoken extensively about the therapeutic options available to women whose fetuses have congenital heart disease. Her recommendation unequivocally is termination of the pregnancy, even for simple lesions like coarctation of the aorta or pulmonary stenosis. Obviously this brings in ethical and other issues. Would you comment on other therapeutic options that would be available in the context of the economic issues involved in the treatment of such complex disease?

Dr. Reddy. Termination of pregnancy as advocated by Dr. Allen is a highly debatable ethical issue. I think this question should be answered not only by doctors but also by sociologists, philosophers, ethicists, economists, politicians, and law makers.

Regarding other modalities of therapy for fetal cardiac lesions, certain important areas require further careful investigation. For example, if interventional cardiologists can gain safe access to the fetal heart, lesions like critical stenosis and restricted foramen ovale will be amenable to minimally invasive intervention. In addition, fetal molecular and genetic therapies may become a reality in the future. One area that we are investigating is induction of fetal immunotolerance for possible neonatal transplantation in all cases of complex congenital heart disease.

Research in the area of fetal intervention, although expensive, deserves continued support because of the enorinous potential benefits.

Dr: Verrier. It is very important to realize that if we are able to alter the patterns of blood flow in utero, then the single-ventricle physiology very well may be avoided. The limiting factor in congenital heart disease is dealing with complex single-ventricle physiology. Thus this research maintains hope that we may be able to alter those patterns in utero with relatively simple interventions, and the type of work that has been continued at UCSF will help us reach that goal.

Dr. Margaret Allen (Seattle, Wash.). Have you looked at bypass times that are longer than 30 minutes? Is there a limit to what you can get away with?

Dr. Reddy. We have at the moment only evaluated up to 30 minutes, but for acute studies we have performed bypass times up to 1 hour with good preservation of placental function with the use of this new circuit. We have not looked at the effect on survival yet.

\section{1-800-55-MOSBY}

This number links you to the full text of articles published in over 25,000 journals, including all Mosby journals. MOSBY Document Express $^{\circledR}$, a rapid response information retrieval service, provides quick turnaround, 24-hour availability, and speedy delivery methods. For inquiries and pricing information, call our toli-free, 24-hour order line: 1-800-55-MOSBY; outside the United States: 415-259-5046; fax: 415-259-5019; E-mail: mosbyexp@class.org. 